\title{
Enhanced STL
}

\author{
Tong Wu $\cdot$ Edmund H. M. Cheung
}

Published online: 20 December 2006

(C) Springer-Verlag London Limited 2006

The originally published reference list of this article unfortunately contained a mistake.

Incorrect reference:

15. Jacob GGK, Kai CC, Mei T (1999) Development of a new rapid prototyping interface. Comput Ind 39:61-70 Correct reference:

15. Gan JGK, Chua CK, Tong M (1999) Development of a new rapid prototyping interface. Comput Ind 39:61-70

The online version of the original article can be found at http://dx.doi. org/10.1007/s00170-005-0001-5.

T. Wu $\cdot$ E. H. M. Cheung

Department of Manufacturing Engineering and Engineering

Management, City University of Hong Kong,

Hong Kong, SAR, People's Republic of China

T. $\mathrm{Wu}(\bowtie)$

Huazhong University of Science and Technology,

G3-09-06, Wuhan 430074, People's Republic of China

e-mail: Mr.wutong@plink.cityu.edu.hk 